\title{
INTRODUÇÃO A UM ESTUDO DO VERSO DE ALBERTO RAMOS
}

\section{AN INTRODUCTION TO A STUDY OF ALBERTO RAMOS' VERSE}

\author{
Recebido: 15/09/2020 Aprovado: 30/11/2020 Publicado: 10/01/2021 \\ DOI: $10.18817 /$ rlj.v4i02.2380
}

Alckmar Luiz dos Santos ${ }^{1}$

Orcid id: https://orcid.org/0000-0002-7896-0103

Thais Piloto da Silva ${ }^{2}$

\begin{abstract}
Resumo: Esse artigo tem por objetivo analisar uma tradução em versos do poeta brasileiro Alberto Ramos. O poeta, classificado muitas vezes como um parnasiano, é tido por muitos como o precursor do verso livre no Brasil, por Péricles Eugênio da Silva Ramos, entre outros. O foco do estudo é, assim, a métrica dos versos do poeta e, a partir da análise desses versos, será discutido se suas características realmente o fazem se aproximar de uma produção fora da métrica tradicional que apontaria para o verso livre. Para isso, analisaremos Poemas do Mar do Norte (1894), tradução de Die Nordsee, de Heirich Heine.
\end{abstract}

Palavras-chave: Alberto Ramos, verso livre, métrica.

Abstract: This article aims to analyze a translation in verses by Alberto Ramos. The poet, often classified as Parnassian, is considered the precursor of the free verse in Brazil, by Péricles Eugênio da Silva Ramos, among others. The focus of the study is, therefore, the metric of the poet's verses and, based on the analysis of these verses, it will be possible to discuss whether their characteristics really bring him closer to a production outside the traditional metric that would point to the free verse. For that, we will analyze Poems of the North Sea (1894), translation of Die Nordsee, by Heirich Heine.

Keywords: Alberto Ramos, free verse, metric.

\section{Introdução}

Alberto Ramos, de fato, é um poeta pouco conhecido, de quem pouco se fala (quando se fala) nos manuais de história literária, mas cuja obra levanta questões relevantes para o estudo do verso, como se pode ver na bibliografia abaixo, especificamente nas obras em que ele é mencionado. Em praticamente todas as

\footnotetext{
1 Possui graduação em engenharia eletrônica, pela Universidade Estadual de Campinas (1983), mestrado em Teoria e História Literária pela Universidade Estadual de Campinas (1989) e doutorado em Estudos Literários pela Université Paris VII (1993). Desde 1994, é professor de Literatura Brasileira da Universidade Federal de Santa Catarina (UFSC). E-mail: alckmar@gmail.com

2 Atualmente é graduanda de Letras - Língua Portuguesa e Literaturas, na Universidade Federal de Santa Catarina, e bolsista no Programa Institucional de Bolsas de Iniciação à Docência da CAPES. Em 2019 participou do Programa Institucional de Bolsas de Iniciação Científica do CNPq no projeto "Literatura brasileira e meio digital - bibliotecas, bancos de dados, ferramentas computacionais". E-mail: thaispilotoo@gmail.com
} 
referências, ao lado de considerações curtas sobre sua obra e vida, aparece apenas a menção a seu papel na introdução do verso livre no Brasil.

Alberto Ferreira Ramos, - seu nome completo - nasceu em Pelotas, Rio Grande do Sul, no ano de 1871, e faleceu no Rio de Janeiro, em 1941. Além de poeta, era jornalista, advogado e dirigiu o jornal O Comércio. Por mais que sua produção não tenha sido tão longa, ela foi bem diversificada. Temos um livro em francês, um em prosa, e obras poéticas que utilizam diferentes tipos de versos e ritmos. Entre estas últimas, temos: Elegias e Epigramas (1919); O Último Canto do Fauno (1913); Poemas (1934); Le chant de bienvenue pour le roi (1920). Foi com o pseudônimo de Marcos de Castro que saiu publicado seu primeiro livro, Poemas do Mar do Norte (1894), na verdade uma tradução de poemas de Heinrich Heine. Além disso, Alberto Ramos também foi tradutor de Nietzsche e autor de um volume de poemas em prosa Prosas de Ariel (1937).

A busca por menções a Alberto Ramos não foi numerosa. Acrescido ao fato de sua biografia ser lacunar, não são tão frequentes quanto se desejaria as referências a ele, em livros ou em artigos de periódicos disponíveis na Hemeroteca digital. Nesta, a busca por Alberto Ramos ou por Marcos de Castro, no período de 1890 a 1899, quando começou a publicar, não trouxe nenhuma ocorrência; já no período seguinte, elas aparecem mais, embora a imensa maioria seja referente a Marcos e Albertos que não são o nosso poeta. Ainda assim, pouco numerosos, os poucos dados recolhidos na Hemeroteca digital foram importantes para situar a recepção do poeta pelos intelectuais (leitores e escritores) de sua época.

Já nos manuais e estudos de história literária, em mais de uma ocasião, aparece o comentário de que seus versos destoam do padrão da época, situando-se tanto dentro como fora da métrica tradicional, o que o leva a ser considerado, como já se afirmou acima, o precursor do verso livre no Brasil. Isso está, por exemplo, no livro Do Barroco ao Modernismo (1979) e no artigo Introdução ao Parnasianismo brasileiro (1989), ambos de Péricles Eugênio da Silva Ramos.

No jornal O Paiz, já se havia destacado, em 1909, que Alberto Ramos se diferenciava por não seguir ritmo e métrica tradicionais. Luís da Câmara Reys (1909, p. 1) aí pontua que "as suas estrofes tem quase sempre um ritmo imprevisto e irregular e, por vezes, talvez propositalmente, não tem ritmo algum". Essa era, portanto, uma questão que já chamava atenção na sua época. 
Para verificar a premissa de que seria Alberto Ramos um dos introdutores do verso livre na literatura brasileira, serão analisados elementos de construção do verso e do ritmo poético em sua obra, especificamente em Poemas do Mar do Norte (1894). Quanto ao fato de que teria sido ele o introdutor do versilibrismo, a confirmação dessa hipótese dependeria de uma pesquisa muitíssimo mais extensa na produção poética daquele período e estaria sempre sob o risco de outros dados serem descobertos, ou seja, que outros poetas, antes de Alberto Ramos, tenham utilizado esse recurso, o que invalidaria o seu ineditismo.

\section{O verso parnasiano}

Para verificar o possível uso do verso livre por Alberto Ramos, é necessário elencar algumas características formais do verso parnasiano (época literária de que nosso poeta é contemporâneo) que teriam de ser modificadas ou mesmo ignoradas, para se poder falar de uma aproximação com o versilibrismo. Vale enfatizar que o que se considera como hábitos de versificação dos parnasianos não aparece de forma total e rígida nas obras dos principais nomes do período, Bilac, Alberto de Oliveira e Raimundo Correa. Dentre esses três poetas, apenas Alberto se aproximaria mais do que manuais e artigos da época apregoam como elementos sine quibus non da arte de poetar parnasiana, muito embora alguns, como Eugênio Gomes (1957), falem de elementos simbolistas em sua obra (vide referência ao final). Em Bilac, a presença de elementos românticos é evidente. Em Raimundo Correia, a opção, por vezes, por uma poética de reflexão e angústia existencial se afasta da impassibilidade tão defendida pelos críticos e teóricos, tanto os daqui, quanto os originais da França (especialmente Leconte de Lisle).

Já alguns companheiros de Academia e de concepção literária, contemporâneos dos três da tríade parnasiana, dispõem-se, por exemplo, a prefaciar obra de Catulo da Paixão Cearense (Luiz Carlos - este, com um soneto tipicamente parnasiano - , Afrânio Peixoto, Humberto de Campos), Meu sertão, em que derramam elogios a um poeta que, em muita coisa, é distante da técnica parnasiana. Isso mostra que a utilização de elementos temáticos, semânticos e imagéticos poderia não ser suficiente para configurar a adesão evidente de um poeta ao Parnasianismo, uma vez que há uma mistura de características poéticas que não se restringem ao que os 
manuais e as reflexões teóricas (frequentemente prescritoras) definem como parnasianas.

Dito de outra maneira, a teoria da expressão poética parnasiana era bem mais ortodoxa do que a prática, o que se pode verificar em manuais de versificação daquela época, assim como em artigos escritos então, como são exemplos o Tratado de versificação (1905), de Bilac e de Guimarães Passos, e os artigos de Alberto de Oliveira listados nas referências bibliográficas abaixo. Isso também ocorre nos manuais de história literária publicados posteriormente. Alfredo Bosi, em sua História concisa da Literatura Brasileira, cuja primeira edição é de 1970, define o Parnasianismo a partir do que ele caracteriza como:

seus traços de relevo: o gosto da descrição nítida (a mimese pela mimese), concepções tradicionalistas sobre metro, ritmo e rima e, no fundo, o ideal da impessoalidade que partilhava com os realistas do tempo" (BOSI, 2017, p. 233).

Isso salienta o que é afirmado repetidamente, isto é, que o Parnasianismo visava à arte pela arte, o que faria com que esses poetas estivessem preocupados com o erudito e o belo, com a busca de versos com rigor formal. Além disso, Alfredo Bosi salienta que os parnasianos condenavam o "relaxamento" métrico dos românticos, que os versos deveriam seguir as regras métricas descritas nos manuais de metrificação. Contudo, em nenhum momento se define com mais clareza o que seriam exatamente tais "concepções tradicionalistas sobre metro", remetendo, subrepticiamente, aos escritos dos próprios parnasianos.

Péricles Eugênio da Silva Ramos (1959, 1979), ao contrário, discute a técnica de versificação do Parnasianismo com mais profundidade, com mais detalhes. É certo que ele é um tanto genérico em Do Barroco ao Modernismo (1979), em que destaca que a produção parnasiana era mais rígida e que a diretriz principal desse período ronda "a correção métrica, a correção gramatical, o vocábulo e a expressão precisos" (1979, p. 174). Todavia, em O verso romântico e outros ensaios (1959), ele entra abertamente em questões mais específicas da técnica do verso, apontando um elemento que foi talvez a principal diretriz deste trabalho: o emprego muito frequente da sinérese por parte dos parnasianos, ao contrário dos românticos.

Diante disso tudo, não seria nada equivocado afirmar que a exigência de uma técnica parnasiana perfeita era imposta, naquele momento, aos poetas menos conhecidos e mantida, posteriormente, pelos trabalhos de história literária. Mas o que 
seria, então, exatamente, esse estilo parnasiano de fazer versos? Se, como dissemos acima, elementos temáticos, semânticos e imagéticos não têm validade total para caracterizar algum poema como parnasiano, talvez um levantamento de dados estilométricos dos poetas da época, referentes à construção dos versos (como ritmos, métricas, processos de acomodação silábica) possa lançar alguma luz a essa discussão. De toda maneira, dada a dispersão de características, ou seja, levando em conta as disparidades entre os poetas, no que toca às soluções formais que dão à construção de seus versos, faz-se necessário definir alguma obra ou algum poeta como sendo o padrão do Parnasianismo, o que nos levou a escolher aquele que, dentre todos, é sempre lido e apontado como parnasiano típico - Alberto de Oliveira. É com ele, com sua obra, com seus versos, que vamos comparar os versos de Alberto Ramos e medir o distanciamento que seus versos vão tomando do que seria o verso medido tradicional, em direção ao que pode ser, então, a busca do verso livre na expressão poética.

\section{O verso de Alberto Ramos}

Um dos pontos que se deve considerar é o fato de que Alberto Ramos usa diversos tipos de versos em suas produções, desde poemas curtos e diretos até poemas longos, misturando versos metrificados e sem métrica. Péricles Eugênio da Silva Ramos, em Do Barroco ao Modernismo (1979), afirma que nosso poeta é responsável por trazer o verso livre ao Brasil, com a tradução do livro Poemas do Mar do Norte, livro de H. Heine, e ainda frisa que o poeta-tradutor tinha consciência de que produzia uma "prosa ritmada", o que poderia ser considerado o início de uma escrita voltada ao verso livre, ainda que não se encaixe no que virá depois, com o Modernismo. Vale observar mais de perto um dos poemas presentes na obra, intitulado "Perguntas":

\footnotetext{
Junto do mar, do vasto mar noturno,

está um adolescente

com o coração cheio de dores

e a cabeça cheia de dúvida,

e com lábios trêmulos interroga as ondas:
} 
"Oh! explicai-me o enigma da vida,

o eterno, calamitoso enigma

sobre o que tantas cabeças parafusaram,

cabeças de barretes hieroglíficos,

cabeças de turbantes e de gorros pretos,

cabeças metidas em perucas,

e mil outras pobres, transpirantes, cabeças humanas

Dizei-me, que vem a ser o homem?

donde veio? para onde vai?

Quem mora lá em cima nas estrelas de ouro?"

As ondas murmuram o seu perpétuo murmúrio,

sibila o vento, voam as nuvens,

no céu cintilam as estrelas,

frias e indiferentes,

e um doido espera a resposta.

Esse poema, composto por três estrofes com um total de vinte versos, nos mostra técnicas usadas por Alberto Ramos que parecem realmente ultrapassar a tradição métrica do Parnasianismo. O primeiro verso é formado por um decassílabo com acento na quarta, na sexta e na décima sílaba, com possíveis acentos secundários na primeira e oitava sílaba. O segundo verso é um hexassílabo com acentuação na segunda e sexta sílaba com forte sinalefa em "está um". No terceiro verso temos um octossílabo com acento na quarta e oitava sílaba, com ectlipse em "com o". O quarto verso também é classificado como um octossílabo com acento na terceira, quinta e oitava sílabas. Fechando essa estrofe, o quinto verso poderia ser um dodecassílabo com acento na terceira, quinta, oitava (tonificada), décima e décima segunda sílaba, contudo esta parece ser a opção menos viável, pois impõe-se, de fato, sua concretização como um duplo pentassílabo (vale lembrar que o octossílabo imediatamente anterior também traz acento na quinta sílaba).

Tomando a segunda estrofe, temos no primeiro verso, ou um decassílabo acentuado na primeira, quarta, sexta e décima sílaba, com um suarabácti em "enigma", ou um octossílabo, se utilizamos sinalefa em "Oh! ex..", tendo sua acentuação na terceira, quinta e oitava sílaba. O segundo verso dessa estrofe pode ser decassílabo, se fazemos dialefa no início (o / eterno), com a acentuação na terceira, oitava e décima sílaba, e um acento secundário na sexta (com atonização 
forçada). O terceiro verso é dodecassílabo, acentuado na quarta, sétima e décima segunda sílabas, com possível acento secundário na décima (no caso, também com atonização forçada). O quarto verso é um decassílabo que, com uma sinérese em /hie/roglíficos, fica acentuado na segunda, sexta e décima sílaba. O quinto verso volta ao dodecassílabo, acentuado na segunda, sexta, décima e décima segunda sílaba. $\mathrm{O}$ sexto verso já apresenta uma mudança sensível com relação ao padrão par da métrica, que vinha sendo seguido até aqui (ainda que o último verso da primeira estrofe seja um duplo pentassílabo, ele é, de fato, um... duplo). Temos, agora, um eneassílabo, acentuado na segunda, quinta e nona sílaba. Há irregularidade métrica, evidentemente, mas o acento na quinta traz o ritmo do pentassílabo que já foi utilizado antes. A sétima linha dessa segunda estrofe não tem como ser único, pois contaria quinze sílabas. Uma possibilidade seria concretizá-la como um verso duplo, composto de um eneassílabo (acentuado na segunda, na quinta e na nona sílabas) e de um pentassílabo (acentuado na segunda e na quinta sílabas).

A irregularidade da metrificação, no caso, seria atenuada pela presença de eneassílabo e pentassílabo, que já aparecem antes (sem contar que, novamente o eneassílabo traz a quinta sílaba acentuada). Na mesma toada, o oitavo verso é um eneassílabo, acentuado na segunda, quinta (novamente!), sétima e nona sílabas. $\mathrm{O}$ nono verso é novamente um eneassílabo, se fazemos dialefa entre ra e on, em "para onde", com acento na terceira, sétima e nona sílaba, com a possibilidade de acento secundário na primeira sílaba. O último verso dessa segunda estrofe volta ao dodecassílabo, acentuado na segunda, quarta, sexta (até aí, em ritmo iâmbico), décima e décima segunda sílaba (retomando, ao final, o mesmo ritmo iâmbico).

A terceira e última estrofe desse poema inicia com um dodecassílabo que, com ectlipse em "murmu/ram o/", fica acentuado na segunda, quinta, sétima, nona e décima segunda sílaba (nem é preciso chamar a atenção para a presença de uma quinta sílaba novamente acentuada). O segundo verso poderia ser um eneassílabo com ritmo inicial iâmbico, acentuado na segunda, quarta, sexta e nona sílaba; no caso, a quinta sílaba, diferentemente do que ocorre em versos anteriores, não leva acento rítmico. O terceiro verso, nesse caso, seria um octossílabo com acento na segunda, quarta e oitava sílaba. Contudo, se usamos ectlipses em ambos, a configuração rítmica e métrica se alteraria. Nesse caso, o segundo seria agora um octossílabo, com a junção de am e as em vo/am as/; já o verso seguinte seria então um heptassílabo, 
acentuado na segunda, quarta e sétima sílabas, pela junção dos mesmos am e as em cinti/lam as/. O quarto verso é um hexassílabo acentuado na primeira e na sexta sílabas, sendo reforçada, como acentos secundários, a segunda sílaba de "indiferentes". Por fim o último verso poderia ser um heptassílabo acentuado na segunda, na quarta e na sétima sílabas. Contudo, se o final parece apontar para uma retomada do padrão rítmico, ele poderia ser concretizado como um octossílabo com acentos na segunda, na quarta e na oitava sílabas, se utilizamos dialefa em "espera/ a"; se a dialefa for posta no início, em "e /um", os acentos aparecem na terceira, na quinta e na oitava.

Com a análise acima, é possível observar que Alberto Ramos tenta abrir o sistema métrico tradicional, acumulando, num só poema, métricas e ritmos bem variados, sem descuidar de estabelecer certas linhas de continuidade, como o uso de métricas pares ou a repetição da quinta sílaba acentuada. Outros elementos, por não serem comuns - sobretudo nas técnicas parnasianas -, chamam a atenção, como o uso de alguns metaplasmos (especificamente a dialefa e a ectlipse), o emprego de versos compostos (se o duplo pentassílabo tem larga utilização em nosso Romantismo, o mesmo não se pode dizer da junção de eneassílabo e pentassílabo). Vale também mencionar o uso de dodecassílabos incomuns, tanto no Brasil, quanto na França. Nesse último caso, na poesia brasileira, esse metro aparecia como alexandrino ou como tripartido (com acentos principais na quarta, na oitava e na décima segunda sílabas), o que não ocorre nesse poema. Observe-se também que mesmo a combinação, numa mesma estrofe, de versos pares (decassílabo, hexassílabo, octossílabo e dodecassílabo) e ímpares (pentassílabo, heptassílabo e eneassílabo) era muito incomum. Alberto Ramos lança mão do sistema versificatório tradicional (e, àquela altura, não havia como ser diferente), ao mesmo tempo tenta forçar esse sistema para usos menos comuns, não previstos nos manuais de metrificação.

De outro lado, não se pode esquecer que esse poema é, na verdade, uma tradução, o que impõe o exame do original. Os versos em Alemão escritos por Heine - Die Nordsee, O Mar do Norte, em tradução direta - não possuem regularidade e 
não seguem o que seria a tradição métrica ocidental ${ }^{3}$, apresentando um ritmo livre (freie Rhythmen), sem rimas e tampouco traz métrica regular. Segundo Adolphe Bossert (1904, p. 807-822), nessa obra de Heine,

\begin{abstract}
La forme s'adapte merveilleusement aux sujets; ce n'est plus la petite strophe de quatre vers courts à trois ou quatre accents, c'est le rythme libre, où le vers s'allonge et se rétrécit, selon l'objet qu'il doit peindre, et où toutes les sonorités et toutes les cadences sont calculées avec un art d'autant plus délicat qu'il se dérobe à l'analyse. Ici, dans le fond comme dans la forme, Henri Heine a été créateur. ${ }^{4}$
\end{abstract}

Sem rimas, portanto, tampouco sem métrica uniforme, esses versos do poeta alemão são apontados com frequência como uma das fontes do verso livre que se consolidou entre as literaturas de línguas românicas a partir do Simbolismo europeu. Não se pode separar, provavelmente, essa forma mais livre dos versos daquilo que constituiu a tradição poética dos países de línguas germânicas. No verbete "verso livre" do E-dicionário de Termos Literários, todos os exemplos são tirados de escritores ingleses ou alemães:

Já na era da Rainha Vitória alguns poetas escreviam versos irregulares com rimas, como Christina Rossetti, Coventry Patmore, e T. E. Brown. Além disso, o poema 'Discharged' de W. E. Henley $(1849$ - 1903) e os poemas 'The LightKeeper' e 'The Cruel Mistress' de Robert Louis Stevenson (1850 - 1894) são bons exemplos preliminares do verso livre. Os 22 poemas de Heinrich Heine (1797 - 1856), considerado ainda hoje um dos mais significativos poetas alemães do século XIX, publicados no Buch der Lieder (1827), contribuíram para o desenvolvimento do verso livre entre os poetas mais consagrados. Mesmo a Threnodia Augustalis de Dryden (1631 - 1700), o Samson Agonites de Milton (1608 - 1674) e um ou outro poema da House of Fame de Chaucer (c. $1343-1400)$ adotaram o verso libre. ${ }^{5}$

Em um artigo publicado em 1998, Isabelle Kalinowski discute as traduções feitas das obras de Heine, particularmente desses versos baseados no freie Rhythmen. Diante da dificuldade da empreitada, isto é, de traduzir versos sem rima e

3 As observações concernentes aos versos em Alemão de Heine, foram gentilmente feitas por Berthold Zilly, a quem agradecemos a paciência e a generosidade, sempre disponíveis, mas nunca suficientemente louvadas!

4 Tradução nossa: A forma se adapta muito bem aos assuntos; não é mais a pequena estrofe de quatro versos curtos com três ou quatro acentos, é o ritmo livre em que o verso se alonga e se encurta, de acordo com o objeto que ele deve desenhar, e onde todas as sonoridades e todas as cadências são calculadas com uma arte tão delicada que se furta à análise. Aqui, tanto no fundo, quanto na forma, Heine foi criador.

5 E-dicionário de Termos Literários. Disponível em ttps://edtl.fcsh.unl.pt/encyclopedia. Acesso em: $18 / 08 / 2020$ 
com metrificação irregular, elementos um tanto estranhos às poéticas dos países de línguas românicas, os tradutores seguiram diferentes caminhos. Gérard de Nerval optou por uma tradução em prosa; já Maurice Pellisson mantém em versos, mas os traduz com rima. Dessa forma, ganha ainda mais relevo a tradução de Alberto Ramos, justamente pela tentativa de se aproximar o mais possível do que foi feito por Heine, tentando criar, em português, o freie Rhythmen do original alemão.

Dessa maneira, por aparentarem ser uma tradução mais fiel, esses versos livres de Alberto Ramos parecem ser devidos às características dessa obra de Heine, mais do que uma inclinação do poeta brasileiro para romper com as cadeias da versificação tradicional parnasiana. Se esta segunda hipótese não pode ser excluída, a primeira é quase inquestionável. Contudo, se levamos em conta os versos mais livres que vão aparecer mais tarde em sua obra, é quase certo que tenha sido justamente esse exercício de tradução que o colocou no caminho do versilibrismo.

Pode ser interessante comparar um dos poemas, no original e na tradução. Mesmo para quem não é versado no Alemão, alguns elementos se destacam:

\section{Fragen}

Am Meer, am wüsten, nächtlichen Meer Steht ein Jüngling-Mann,

Die Brust voll Wehmut, das Haupt voll Zweifel, Und mit düstern Lippen fragt er die Wogen:

"O löst mir das Rätsel des Lebens,

Das qualvoll uralte Rätsel,

Worüber schon manche Häupter gegrübelt, Häupter in Hieroglyphenmützen,

Häupter in Turban und schwarzem Barett, Perückenhäupter und tausend andre Arme, schwitzende Menschenhäupter Sagt mir, was bedeutet der Mensch? Woher ist er kommen? Wo geht er hin? Wer wohnt dort oben auf goldenen Sternen?"

\section{Perguntas}

Junto do mar, do vasto mar noturno, está um adolescente com o coração cheio de dores e a cabeça cheia de dúvida, e com lábios trêmulos interroga as ondas:

"Oh! explicai-me o enigma da vida, o eterno, calamitoso enigma sobre o que tantas cabeças parafusaram, cabeças de barretes hieroglíficos, cabeças de turbantes e de gorros pretos, cabeças metidas em perucas,

e mil outras pobres, transpirantes, cabeças humanas -

Dizei-me, que vem a ser o homem? donde veio? para onde vai?

Quem mora lá em cima nas estrelas de ouro?" 
Es murmeln die Wogen ihr ew'ges Gemurmel,

Es wehet der Wind, es fliehen die Wolken,

Es blinken die Sterne, gleichgültig und kalt,

As ondas murmuram o seu perpétuo

Und ein Narr wartet auf Antwort.

murmúrio,

sibila o vento, voam as nuvens,

no céu cintilam as estrelas,

frias e indiferentes,

e um doido espera a resposta.

Apenas dois versos do original não foram traduzidos como verso único: Die Brust voll Wehmut, das Haupt voll Zweifel (o terceiro da primeira estrofe; em tradução literal, peito pleno de tristeza, cabeça plena de dúvida) e Es blinken die Sterne, gleichgültig und kalt (o terceiro da última estrofe; as estrelas piscam, indiferentes e frias). Nos demais, as imagens e as extensões métricas se equivalem aproximadamente. No original, vale ressaltar o predomínio do iambo, alternando com o troqueu e com o dáctilo 6 . Contudo, a tradução é diferente. Realizando o mapeamento dos grupos silábicos mais prováveis (isto é, mais próximos das teorias dos versos da época), obtém-se o esquema a seguir. Nele, IAM equivale a iambo; TRO, a troqueu; ANA, a anapesto; DAC, a dáctilo; PE4, a peônico de $4^{a}$.

6 Mais uma vez, valemo-nos da sabedoria de Berthold Zilly. No caso da denominação dos grupos rítmicos, utilizamos a nomenclatura da versificação clássica, que, sabemos bem!, não poderia ser rigorosamente aplicada a versos com ritmo baseado na intensidade (e não na extensão), mas não deixa de ser útil por fornecer uma terminologia que muitos estudiosos compartilham. 
Junto do mar, do vasto mar noturno,

está um adolescente

com o coração cheio de dores

e a cabeça cheia de dúvida,

e com lábios trêmulos interroga as ondas:

"Oh! explicai-me o enigma da vida, o eterno, calamitoso enigma sobre o que tantas cabeças parafusaram, cabeças de barretes hieroglíficos, cabeças de turbantes e de gorros pretos, cabeças metidas em perucas,

e mil outras pobres, transpirantes, cabeças humanas Dizei-me, que vem a ser o homem? donde veio? para onde vai?

Quem mora lá em cima nas estrelas de ouro?"

As ondas murmuram o seu perpétuo murmúrio, sibila o vento, voam as nuvens, no céu cintilam as estrelas, frias e indiferentes,

e um doido espera a resposta.
(10) _ U U _ U _ U _ U _ U - DAC / TRO / TRO / TRO

(6) $U_{-} U \underline{U} U_{-} U-I A M / I A M / I A M$

(8) $U \cup U \_$_ U U _ U - PE4 / PE4

(8) $U U_{-} U_{-} U U_{-} U-$ ANA / IAM / ANA

(5-5) U U_U_U // U U _ U_ U - ANA / IAM // ANA / IAM

(8) U U_ U U U U U U - ANA / IAM / ANA

(10) U U _ U U U U _ U U - ANA / ANA / IAM / IAM

(12) $\underline{U} \cup U_{-} \cup U U_{-} \cup \cup U U \_U-D A C / D A C / D A C / A N A$

(10) U_ UUU_ $U U U$ _ U U - IAM / PE4 / PE4

(12) U_UUU_UUU_U_U - IAM / PE4 / PE4 / IAM

(9) $U_{-} U U_{-} U U U_{-} U-I A M /$ ANA / PE4

(9-5) U_ UU_ UUU_ U // U U U U U - IAM / ANA / PE4 // IAM / ANA

(9) U_U U_U_U_U - IAM / ANA / IAM / IAM

(9) $U U_{-} \cup \cup U_{-} U_{-}$- ANA / PE4 / IAM

(12) U_ U_ U_U U U _ U _ U - IAM / IAM / IAM / PE4 / IAM

(12) U_U U_U_U_U U U U - IAM / ANA / IAM / IAM / ANA

(9) $U_{-} U_{-} U_{-} U U_{-} U-$ IAM / IAM / IAM / ANA

(8) $U_{-} U_{-} U U U_{-} U-I A M / I A M / P E 4$

(6) _ UU $\underline{U} U_{-} U-T R O /$ IAM / IAM

(7) $U_{-} U_{-} U U_{-} U-I A M / I A M / A N A$ 
As três estrofes da tradução mantêm a simetria do original: aquela se compõe de 5, 10 e 5 versos cada uma; este traz 4, 10 e 4. Outra semelhança é o predomínio de grupos iâmbicos, 35 de um total de 73 (quase metade, 48\%); os anapestos somam 18 (pouco menos de 25\%); os peônicos de 4⿳a são 11 (15\%); dos dáctilos, temos 4 (5,5\%); o mesmo para os troqueus, ou seja, também um total de 4. Contudo o que nos interessa são algumas particularidades dos versos de Alberto Ramos. Como no original alemão, há também predomínio dos iambos, mas, diferentemente do que apontou Berthold Zilly, a alternância é feita com anapestos e peônicos de $4^{a}$, e não com troqueus e dáctilos. De outro lado, saltam aos olhos algumas peculiaridades da tradução de Alberto Ramos. Dos 20 versos, 3 apresentam ritmo descendente, isto é, dois iniciam com dáctilo e um com troqueu, respectivamente, verso 1 da estrofe $1^{7}$, verso 3 da estrofe 2 e verso 4 da estrofe 3 . Desconhecemos estatísticas referentes à ocorrência desses ritmos, mas são muito raros; numa observação en vol d'oiseau, nos parece bem menos do que os $15 \%$ dessa tradução. Vale dizer que, desses grupos descendentes, apenas o primeiro conserva-se assim até o final. $O$ verso 3 da estrofe 2 termina em anapesto; o 4 da estrofe 3, começa com um troqueu que é sucedido por dois iambos.

Outra diferença desses versos de Alberto Ramos com respeito à versificação parnasiana mais ortodoxa está nas métricas adotadas. Há predomínio de versos pares. Estes são em número de 13 e os ímpares perfazem 7, sendo que, curiosamente, o último destes - e também último do poema - é um heptassílabo, ou seja, um verso de 7 sílabas. Contudo, de fato, seriam 9 os versos ímpares, pois entre eles estão os dois únicos versos compostos: um bipentassílabo e um eneassílabo conjugado a um pentassílabo. Entre os pares, há 2 hexassílabos, 4 octossílabos, 3 decassílabos e 4 dodecassílabos. Não apenas pela alternância entre versos pares e ímpares, mas também pela diversidade dos pares, seriam raríssimos os exemplos dessa variedade métrica na poesia brasileira produzida até a década de 20 do século passado. Não pudemos encontrar um só exemplo, numa pesquisa feita de forma mais panorâmica.

7 Vale lembrar que, nessa ordenação numérica dos versos, os compostos foram computados como um verso. 
Em Portugal, aí sim, cabe destacar a obra de Guerra Junqueiro, em que sobressai a diversidade de metros, principalmente nos poemas mais longos. Num único volume, A morte de $\mathrm{D}$. João - dos primeiros que publicou o poeta português - temos uma ampla gama de metros: tetrassílabos, redondilhas menores, bipentassílabos, hexassílabos (sozinhos ou revezando com decassílabos e alexandrinos), redondilhas maiores, decassílabos e alexandrinos; além de versos de estrutura dramática, em que um único aparece em duas linhas sucessivas, como a simular ou mesmo a concretizar o diálogo teatral versificado. Teria sido o possível versilibrismo de Alberto Ramos inspirado no poeta português? É possível, dada a influência deste nos poetas brasileiros da segunda metade do século $X X$, a despeito da manifesta má vontade de Sílvio Romero para com o autor d'A velhice do Padre Eterno.

Seja como for, mais tarde, isto é, após o exercício de tradução e de assimilação que representou Poemas do Mar do Norte, Alberto Ramos envereda por um caminho em que, manifestamente, a ortodoxia do verso parnasiano fica relegada a segundo plano. É certo que não chega muito perto do verso livre simbolista europeu ou do modernista brasileiro, mas é inegável que abre os grilhões da metrificação mais tradicional. Se examinamos, por exemplo, a "Ode ao campeonato", podemos ver que a utilização de rimas não esconde as linhas mais longas que, quase sempre, vão além do limite de 12 sílabas prescritos pelos tratados de versificação, sem que repitam a mesma quantidade (há versos de 12 sílabas, sim!, mas também há linhas com sílabas mais numerosos, com 13 e 14):

Salve, amplo mar, ridente mar, salve augusto oceano maravilhoso! imenso como o desejo humano

e como ele insofrido e amargo e nunca satisfeito, atormentado mar de incontentado peito!

Tu conduziste a lide nova, a novos céus, a novos feitos as naus errantes no alvorecer dos povos;

as que impelia a glória, erectas pelo mar em fora, retumbantes do choque de armas, sulcando a aurora, 
fendendo o azul, soberbas quinas, alvas caravelas,

e as que a sede implacável do ouro enfunava as velas.

Possivelmente, a construção rítmica estaria aí não mais na isometria, mas possivelmente na sucessão de grupos silábicos homogêneos, como tentou, com outra estratégia e outros resultados, Magalhães de Azeredo. Este poeta, em seu Laudes do Jardim Real de Atenas, quer escapar da metrificação tradicional das línguas românicas, tentando realizar uma atualização dos ritmos extensionais da versificação grega. Teria Alberto Ramos enveredado por aí, isto é, não propriamente por uma renovação do verso em direção ao verso livre inspirado nos simbolistas europeus, mas por uma volta aos primórdios da história do verso? É possível também! Mas isso é especulação que não cabe nos limites deste artigo e será tratado em outro trabalho nosso.

\section{Considerações Finais}

Com todos os pontos trazidos é possível dizer que Alberto Ramos tem grande importância na história do verso livre no Brasil e afirmar que ele foi um dos pioneiros de tal prática escrita. Com isso vemos que Alberto Ramos transitava em diferentes ritmos e tipo de versos, isso mostra, também, a riqueza desse poeta, ele consegue se utilizar de diferentes artifícios em sua produção mostrando grande conhecimento sobre o fazer poético. Alberto Ramos mostra ter conhecimento da métrica tradicional, e a partir dela consegue produzir um novo tipo de verso ainda não costumeiro nos movimentos literários contemporâneos a ele. A partir do uso da métrica tradicional o poeta começa a abrir esse sistema para um uso mais flexível.

Com o presente estudo nota-se, também, a influência que Alberto Ramos teve do verso alemão, com a tradução dos poemas de Heine, com versos que possuem um ritmo e métrica mais livre e não tão presa aos padrões métricos tradicionais usados no Brasil à época. Com isso, podemos ver que Alberto Ramos já fazia um movimento de abertura métrica antes do movimento modernista, quando temos realmente a produção do verso livre que conhecemos.

\section{Referências}

AOIDOS. Disponível em: http://aoidos.ufsc.br. Acesso em: jun. 2020. 
BILAC, Olavo; GUIMARÃES PASSOS, Sebastião Cícero dos. Tratado de versificação. Rio de Janeiro: Livraria Francisco Alves, 1905.

BOSI, Alfredo. História Concisa da Literatura Brasileira. São Paulo: Cultrix, 2017.

BOSSERT, Adolphe. Histoire de la littérature allemande, Paris, Hachette, 1904. Disonível em http://agora.qc.ca/Dossiers/Heinrich_Heine. Acesso em 18/08/2020.

CEARENSE, Catulo da Paixão. Meu sertão. 15. Ed. Rio de Janeiro: A Casa do Livro, s.d.

GOMES, Eugênio. "Alberto de Oliveira e o Simbolismo". Correio da Manhã. Rio de Janeiro: 11 de maio de 1957, p. 9.

KALINOWSKI, Isabelle. "Heine en français: brève historie d'une réception difficile". Romantisme, n. 101, [s. I.], 1998, p. 89-96.

OLIVEIRA, Alberto de. Prefácio: "A arte de fazer versos". In: DUQUE-ESTRADA, Osório. A arte de fazer versos, [s.I.], 1914, p. 23-27.

OLIVEIRA, Alberto de. "A rima e o ritmo: lições professadas na Escola Dramática". Revista do Brasil. Rio de Janeiro; São Paulo: 1916.

OLIVEIRA, Alberto de. "O soneto brasileiro (de Gregório de Matos a Raimundo Correia): Conferência feita na Biblioteca Nacional em 23 de setembro de1918". Revista de Língua Portuguesa - Arquivo de estudos relativos ao idioma e literatura nacionais. Rio de Janeiro: 1920.

OLIVEIRA, Alberto de. "O verso alexandrino na poesia portuguesa: Fragmento de bela e erudita carta a Alberto Faria". Almanaque Brasileiro Garnier. Rio de Janeiro: 1914.

RAMOS, Alberto. Ode ao campeonato. s.n., 1902.

RAMOS, Alberto. Poemas de Alberto Ramos. Rio de Janeiro, RJ: Ariel. 1934.

RAMOS, Alberto. O último canto do Fauno. Rio de Janeiro, 1913.

RAMOS, Péricles Eugênio da Silva. Do Barroco ao Modernismo. Rio de Janeiro: Livros Técnicos e Científicos, 1979.

RAMOS, Péricles Eugênio da Silva. "Introdução ao Parnasianismo brasileiro". São Paulo, SP: Revista da Universidade de São Paulo. 1989.

RAMOS, Péricles Eugênio da Silva. O verso romântico e outros ensaios. São Paulo: Conselho Estadual de Cultura, 1959. 
RAMOS, Péricles Eugênio da Silva. "Origem e evolução do soneto brasileiro". Suplemento literário d'O Estado de São Paulo. São Paulo: 1988, ano VII, número 428, de $1^{\circ}$ de outubro, página 6.

REYS, Luis da Câmara. "Poetas e Prosadores". O Paiz. Rio de Janeiro, 25 dez. 1909. Disponível em: http://bndigital.bn.gov.br/hemeroteca-digital/. Acesso em: nov. 2019.

PASSOS, Sebastião Cícero dos Guimarães; BILAC, Olavo Brás Martins dos Guimarães. Tratado de versificação. Rio de Janeiro, RJ: Livraria Francisco Alves. 1905.

TEXTLOG.DE. Frangen. 2005. Disponível em: https://www.textlog.de/23319.html. Acesso em: 10 jun. 2020. 